\title{
Impact of transfer status on hospitalization cost and discharge disposition for acute ischemic stroke across the US
}

\author{
Ashish Sonig, MD, MS, MCh, 1,5 Ning Lin, MD,, Chandan Krishna, MD, 1,5 \\ Sabareesh K. Natarajan, MD, MS, ${ }^{1,5}$ Maxim Mokin, MD, PhD, ${ }^{1,5}$ L. Nelson Hopkins, MD, ,2,24-6 \\ Kenneth V. Snyder, MD, PhD, ${ }^{1-5}$ Elad I. Levy, MD, MBA, ${ }^{1,2,4,5}$ and Adnan H. Siddiqui, MD, PhD 1,2,4-6 \\ Departments of ${ }^{1}$ Neurosurgery, ${ }^{2}$ Radiology, and ${ }^{3}$ Neurology, School of Medicine and Biomedical Sciences; and ${ }^{4}$ Toshiba Stroke \\ and Vascular Research Center, University at Buffalo, State University of New York; ${ }^{5}$ Department of Neurosurgery, Gates \\ Vascular Institute at Kaleida Health; and ${ }^{6} \mathrm{Jacobs}$ Institute, Buffalo, New York
}

OBJECTIVE In this study, the authors used information provided in the Nationwide Inpatient Sample (NIS) to study the impact of transferring stroke patients from one facility to a center where they received some form of active stroke intervention (intravenous tissue plasminogen activator, thrombectomy, or a combination of both therapies).

METHODS Patient demographic characteristics and hospital factors obtained from the 2008-2010 acute stroke NIS data were analyzed. Discharge disposition, hospitalization cost, and mortality were the dependent variables studied. Univariate analysis and multivariate binary logistic regression analysis were performed. Data analysis focused on the cohort of acute stroke patients who received some form of active intervention (55,913 of 1,311,511 patients in the NIS).

RESULTS When overall outcome was considered, transferred patients had a significantly higher number of other-thanroutine (OTR, i.e., other than discharge to home without home health care) discharge dispositions ( $p<0.0001)$. In multivariate regression analysis including pertinent patient and hospital factors, transfer-in patients had significantly worse OTR discharge disposition ( $p<0.0001$, odds ratio [OR] 2.575, 95\% Cl 2.341-2.832). Mean hospitalization cost including an intervention was $\$ 70,325.11$ for direct admissions and $\$ 97,546.92$ for transferred patients. Transfer from another facility ( $p<0.001$, OR $1.677,95 \% \mathrm{Cl} 1.548-1.817)$ was associated with higher hospitalization cost.

CONCLUSIONS The study showed that hospital cost for acute stroke intervention is significantly higher for a transferred patient than for a direct admission. Moreover, the frequency of OTR discharge was significantly higher among transferred patients than direct admissions. Future strategies should focus on ways and means of transporting patients appropriately and directly to stroke centers.

http://thejns.org/doi/abs/10.3171/2015.4.JNS141631

KEY WORDS acute ischemic stroke; discharge disposition; hospitalization cost; Nationwide Inpatient Sample; thrombectomy; thrombolysis; vascular disorders

$\mathrm{E}$ ACH year, approximately 800,000 individuals experience a new or recurrent stroke. ${ }^{10}$ Mortality data from 2008 indicated that stroke accounts for $1 \mathrm{of} e v-$ ery 18 deaths in the United States, ${ }^{17}$ and by 2030,4 million additional people will have suffered stroke, an increase of $21.9 \%$ in prevalence from $2013 .{ }^{10}$ The number of in- terventions for acute ischemic stroke has increased markedly since the approval of the Merci retriever (Concentric Medical) by the Food and Drug Administration in August 2004. From 1998 to 2008, the stroke death rate fell $34.8 \%$, and the actual number of stroke deaths declined $19.4 \% .^{14}$

Optimal utilization of resources is paramount to the

\footnotetext{
ABBREVIATIONS APR-DRG = All Patient Refined Diagnosis-Related Group; CAD = coronary artery disease; CCS = Clinical Classifications Software; DVT = deep venous thrombosis; ESCAPE = Endovascular Treatment for Small Core and Anterior Circulation Proximal Occlusion with Emphasis on Minimizing CT to Recanalization Times; HCUP = Healthcare Cost and Utilization Project; ICD-9-CM = International Classification of Diseases, Ninth Revision, Clinical Modification; LOS = length of stay; MR CLEAN = Multicenter Randomized Clinical Trial of Endovascular Treatment for Acute Ischemic Stroke in the Netherlands; mRS = modified Rankin Scale; NIHSS = National Institutes of Health Stroke Scale; NIS = Nationwide Inpatient Sample; nos = not otherwise specified; OR = odds ratio; OTR = other than routine; SD = standard deviation; tPA = tissue plasminogen activator; UTI = urinary tract infection.
}

SUBMITTED July 11, 2014. ACCEPTED April 8, 2015.

INCLUDE WHEN CITING Published online October 9, 2015; DOI: 10.3171/2015.4.JNS141631. 
care of acute stroke patients. The duration of time from the onset of symptoms and arrival at a specialized stroke care center often dictates the mode of intervention, after due consideration of the National Institutes of Health Stroke Scale (NIHSS) score and findings on neuroimaging studies. Recent trials have clearly demonstrated the superiority of intraarterial treatment for large vessel occlusion. ${ }^{4,7,11}$ As the volume of stroke interventions and caseloads is increasing with time, knowledge of the proportion of patients who are transferred to a stroke center from a primary hospital and the differences in related costs and outcomes in transferred versus nontransferred patients are of paramount importance.

Several studies analyzing the outcome of stroke patients based on data from the Nationwide Inpatient Sample (NIS) have been published. ${ }^{1-3,6,9,13}$ To our knowledge, no study has investigated the impact of transferring a stroke patient from a primary center to a specialized center on hospitalization cost and outcome. We used 2008-2010 NIS inpatient data to study this effect. The NIS is the largest inpatient care database, representing $20 \%$ of admissions to nonfederal hospitals across the United States.

In 2008, a new variable called "transfer status" was incorporated in the NIS database. This variable denotes whether a patient was admitted to a hospital directly or from another facility. In this study, we used this extra information provided in the NIS database to study the impact of transferring a stroke patient from one facility to a center where he or she received some form of stroke intervention (intravenous tissue plasminogen activator [tPA] or thrombectomy, either alone or in combination). As the extent of a patient's initial disability can affect the outcome, we included severity of disease, All Patient Refined Diagnosis-Related Groups (APR-DRGs), ${ }^{17}$ in our analysis. We included NIS data up to the year 2010, which is just prior to Food and Drug Administration approval of stentretrievers but after the approval of the Penumbra aspiration thrombectomy device (Penumbra, Inc.) and the aforementioned Merci thrombectomy device.

\section{Methods}

The NIS is the largest all-payer inpatient care database that is publicly available in the United States. It contains data from approximately 1000 hospitals sampled to approximate a $20 \%$ stratified sample of US community hospitals. We analyzed 2008-2010 NIS data using Clinical Classifications Software (CCS; http://www.hcup-us.ahrq. gov/) and codes from the International Classification of Diseases, Ninth Revision, Clinical Modification (ICD-9$\mathrm{CM})$ to extract the data.

The following ICD-9-CM diagnosis codes for acute stroke were used in the extraction of data: 433.01 (basilar artery occlusion), 433.11 (carotid artery occlusion), 433.21 (vertebral artery occlusion), 434.0 (cerebral thrombosis), 434.00 (cerebral thrombosis without infarct), 434.01 (cerebral thrombosis without infarction), 434.1 (cerebral embolism), 434.10 (cerebral embolism without infarction), 434.11 (cerebral embolism with infarction), 434.9 (cerebral artery occlusion, not otherwise specified [nos]), 434.90 (cerebral artery occlusion nos without infarct), 434.91 (ce- rebral artery occlusion nos with infarct), and 436 (acute cerebrovascular accident). The following ICD-9-CM procedure codes were used in the analysis of data: 991.0 (infusion of thrombolytic agent) and 397.4, 397.5, and 397.6 (endovascular removal of thrombus/embolus from head and neck vessels).

As several patient factors (including age and comorbid conditions) can affect outcomes, the following covariates were generated from the database to strengthen the analysis: 1 ) age $\geq 65$ years; 2 ) aspiration pneumonia-CCS code 129 ; 3) posterior circulation stroke-ICD-9-CM codes 433.01 (basilar artery occlusion) and 433.21 (vertebral artery occlusion); 4) respiratory disease-CCS codes 125 (acute bronchitis), 126 (other upper respiratory infections), 127 (chronic obstructive pulmonary disease and bronchiectasis), 128 (asthma), 130 (pleurisy, pneumothorax, pulmonary collapse), 131 (respiratory failure, insufficiency, arrest [adult]), 132 (lung disease due to external agents), and 133 (other lower respiratory disease); 5) cardiac conditions (coronary artery disease [CAD]) - CCS codes 100 (acute myocardial infarction), 101 (coronary atherosclerosis and other heart disease), 107 (cardiac arrest and ventricular fibrillation), and 108 (congestive heart failure, nonhypertensive); 6) comorbidity index-the comorbidities provided by the NIS database included in the study were acquired immune deficiency syndrome, alcohol abuse, deficiency anemias, chronic blood loss anemia, congestive heart failure, chronic pulmonary disease, coagulopathy, uncomplicated diabetes, rheumatoid arthritis/collagen vascular diseases, diabetes with chronic complications, drug abuse, hypothyroidism, liver disease, lymphoma, fluid and electrolyte disorders, metastatic cancer, hypertension, other neurological disorders, obesity, paralysis, peripheral vascular disorders, pulmonary circulation disorders, renal failure, solid tumor without metastasis, peptic ulcer disease excluding bleeding, valvular disease, and weight loss. The comorbidity accumulation indices of individual patients ranged from 0 to a maximum of 11 . Quartile analysis was done with patients with $\geq 2$ comorbidities forming the "above the 75th percentile" group, that is, the high-comorbidity cohort, and patients with $<2$ comorbidities forming the low-comorbidity cohort. 7) Secondary intracranial hemorrhage-ICD-9-CM codes 430, 431, and 432; 8) deep venous thrombosis (DVT)-ICD-9-CM codes 451.1, 451.2, 451.81, 451.9, 453.1, 453.2, 453.8, and 453.9; and 9) urinary tract infection (UTI)-ICD-9-CM codes 599.0 and 590.9.

Demographic factors included sex, primary expected payer (insurance status), race, and median household income quartile for the patient's ZIP code.

An earlier study ${ }^{20}$ has shown that hospital factors alone can affect clinical outcome. To understand the influence of hospital factors on patient outcome and complications, the following coded variables in the NIS database were studied: 1) region of hospital (in the NIS database, the US is divided into the following regions: Northeast, Midwest, South, and West), 2) ownership of hospital (government or private), 3) elective versus nonelective admission, 4) location of hospital (rural or urban), 5) bed size of hospital (small, medium, or large), 6) teaching status of hospital (teaching or nonteaching), 7) admission day ${ }^{13}$ (MondayFriday vs Saturday-Sunday), and 8) transfer status/admis- 
sion status (direct admission or transfer-in from another facility).

The NIS variable "total charges" was used to assess the cost incurred by the hospital in the treatment.

Discharge disposition was dichotomized into "routine" and "other than routine" (OTR). ${ }^{20}$ OTR discharge dispositions included final outcomes like transfer to a short-term hospital facility, skilled nursing facility, intermediate care, or home health care; transfer against medical advice; and death. Discharge disposition to home without home health care was considered a routine discharge disposition.

\section{Statistical Methods}

Discharge disposition, hospitalization cost, and mortality were the dependent variables that were studied. Univariate analysis was performed, and variables with a $p$ value $<0.1$ were considered for further analysis using the multivariate binary logistic regression model. Confidence interval, $\mathrm{p}$ value, and odds ratio (OR) were calculated. Statistical analysis was done using SPSS Statistics software, version 20 (IBM Corporation).

\section{Results}

Data from the NIS database for 1,311,511 patients admitted for acute stroke from 2008 to 2010 were reviewed. The mean age of these patients was 71.11 years (range 9-114 years, standard deviation [SD] 14.7 years); 66.26\% of the patients $(n=868,975)$ were elderly ( $\geq 65$ years), and $53.3 \%(n=695,538)$ overall were women The predominant race was white $(59.8 \%, \mathrm{n}=784,334)$. Among the total patient group, $95.7 \%(\mathrm{n}=1,251,868)$ did not receive any active intervention, $3.6 \%(\mathrm{n}=48,362)$ received only tPA, $0.33 \%(n=4342)$ received "tPA and thrombectomy," and "only thrombectomy" was performed in $0.24 \%(n=3209)$. We analyzed data for the cohort of patients $(n=55,913)$ who received some form of active intervention (Table 1).

\section{Transfer Status}

Among 48,362 patients who received only tPA, few (2177 patients [4.5\%]) received this agent after being transferred in from another facility. However, a substantial number of patients who underwent thrombectomy had been transferred in from another facility; $39.07 \%$ of thrombectomy alone were carried out in patients who had been transferred from another facility, and $21.04 \%$ of patients received tPA and thrombectomy after transfer (Table 1). The difference was statistically significant $(\mathrm{p}<0.0001)$.
When overall outcome was considered, patients transferred in from another facility had a significantly higher number of OTR discharge dispositions $(\mathrm{p}<0.0001)$ (Table 1). In the cohort of patients who received only tPA, $30.46 \%$ of direct admissions and $19.43 \%$ of patients with transfer status had routine discharge disposition. Similarly, the cohort of thrombectomy and tPA patients saw a decline in routine outcome percentage from $15.54 \%$ in the direct admissions cohort to $7.66 \%$ in transfer patients. Patients who received only tPA and had transfer status had a significantly $(\mathrm{p}<0.001)$ higher rate of mortality $(\mathrm{p}<0.001)$ (Table 1). In the other cohort, the difference in mortality was not statistically significant (Table 1).

\section{Patient Factors}

The frequency of OTR discharge dispositions significantly increased when patients had pulmonary embolism, pneumonia, aspiration pneumonia, DVT, UTI, secondary hemorrhage, high comorbidity index, posterior circulation stroke, or were elderly ( $>65$ years). In the cohort of patients transferred in from another facility, the significantly higher frequency of these factors persisted, mainly pulmonary embolism ( $\mathrm{p}<0.001)$, pneumonia $(\mathrm{p}<0.0001)$, aspiration pneumonia ( $\mathrm{p}<0.0001)$, UTI ( $\mathrm{p}<0.0001)$, secondary hemorrhage $(\mathrm{p}<0.0001)$, high comorbidity index ( $p<0.0001)$, posterior circulation stroke $(\mathrm{p}<0.0001)$, and age $>65$ years $(\mathrm{p}<0.0001)$.

Posterior circulation stroke was significantly associated with OTR discharge disposition (Table 2) when compared with strokes in other locations. The difference was significant irrespective of transfer status $(\mathrm{p}=0.013$ and $\mathrm{p}=0.048$ for the direct admission and transfer cohorts, respectively).

When mortality was considered, all the above factors were associated with a significant increase in mortality in the cohort of patients who received treatment at the direct facility. However, in the cohort of patients transferred to another facility, only pneumonia ( $\mathrm{p}<0.0001)$, aspiration pneumonia ( $\mathrm{p}<0.027)$, secondary brain hemorrhage $(\mathrm{p}<$ $0.0001)$, and older age ( $p<0.0001)$ had a significant impact on mortality.

We also analyzed APR-DRG risk of mortality and APR-DRG severity of illness subclasses. As the scale ("minor loss of function" to "extreme loss of function" and "minor likelihood of dying" to "extreme likelihood of dying") increased in the APR-DRG mortality and severity subclass, mortality and OTR discharge dispositions increased proportionally and were significant (Table 2).

TABLE 1. Admission type: discharge disposition and mortality

\begin{tabular}{|c|c|c|c|c|c|c|c|c|c|c|}
\hline \multirow[b]{3}{*}{ Intervention } & \multicolumn{8}{|c|}{ Admission Type } & \multirow{2}{*}{\multicolumn{2}{|c|}{$p$ Value }} \\
\hline & \multicolumn{4}{|c|}{ Direct } & \multicolumn{4}{|c|}{ Transfer* $^{*}$} & & \\
\hline & OTR DD & $\begin{array}{c}\text { Routine DD, } \\
n(\%)\end{array}$ & $\begin{array}{c}\text { Mortality, } \\
n(\%)\end{array}$ & Total & $\begin{array}{l}\text { OTR } \\
\text { DD }\end{array}$ & $\begin{array}{c}\text { Routine DD, } \\
n(\%)\end{array}$ & $\begin{array}{c}\text { Mortality, } \\
n(\%)\end{array}$ & Total & Mortality & DD \\
\hline tPA only & 32,115 & $14,070(30.46)$ & $4030(8.72)$ & 46,185 & 1754 & $423(19.43)$ & $245(11.25)$ & 2177 & $<0.001$ & $<0.001$ \\
\hline Thrombectomy + tPA & 2895 & $533(15.54)$ & $750(21.89)$ & 3428 & 844 & $70(7.66)$ & $200(21.28)$ & 914 & 0.998 & $<0.0001$ \\
\hline Thrombectomy only & 1657 & $298(15.24)$ & $455(23.27)$ & 1955 & 1126 & $128(10.20)$ & $278(22.19)$ & 1254 & 0.474 & $<0.001$ \\
\hline
\end{tabular}

$\mathrm{DD}=$ discharge disposition.

* Transferred in from another facility. 
TABLE 2. Mortality and discharge disposition: analysis of patient, hospital, and demographic factors

\begin{tabular}{|c|c|c|c|c|c|c|}
\hline \multirow[b]{2}{*}{ Factor } & \multirow{2}{*}{$\begin{array}{c}\text { Hospital Deaths, } \\
n(\%)\end{array}$} & \multirow[b]{2}{*}{ OTR DD } & \multirow[b]{2}{*}{ Routine DD } & \multirow[b]{2}{*}{ Total } & \multicolumn{2}{|c|}{$p$ Value } \\
\hline & & & & & Mortality & $\mathrm{DD}$ \\
\hline \multicolumn{7}{|l|}{ Admission } \\
\hline Mon-Fri & $4265(10.53)$ & 29,344 & 11,149 & 40,493 & 0.125 & 0.103 \\
\hline Sat-Sun & $1693(10.98)$ & 11,068 & 4352 & 15,420 & & \\
\hline \multicolumn{7}{|l|}{ Hosp bed size* } \\
\hline Small & $1241(8.90)$ & 10,030 & 3907 & 13,936 & $<0.001$ & 0.126 \\
\hline Large & $4652(11.30)$ & 29,905 & 11,266 & 41,171 & & \\
\hline \multicolumn{7}{|l|}{ Hosp control/ownership* } \\
\hline Government, nonfederal & $840(13.08)$ & 4623 & 1800 & 6423 & $<0.001$ & 0.284 \\
\hline Private, nonprofit & $4429(10.53)$ & 30,464 & 11,596 & 42,060 & & \\
\hline Private, investor-owned & $624(9.42)$ & 4847 & 1776 & 6624 & & \\
\hline \multicolumn{7}{|l|}{ Hosp location* } \\
\hline Rural & $204(9.46)$ & 1477 & 679 & 2156 & 0.059 & $<0.001$ \\
\hline Urban & $5689(10.74)$ & 38,457 & 14,494 & 52,951 & & \\
\hline \multicolumn{7}{|l|}{ Hosp region* } \\
\hline Northeast & 1409 (11.51) & 9415 & 2822 & 12,237 & $<0.001$ & $<0.001$ \\
\hline Midwest & $1001(8.95)$ & 8044 & 3137 & 11,181 & & \\
\hline South & $2245(10.82)$ & 14,500 & 6249 & 20,749 & & \\
\hline West & $1304(11.10)$ & 8452 & 3293 & 11,745 & & \\
\hline \multicolumn{7}{|l|}{ Teaching hosp* } \\
\hline $\mathrm{N}$ & $2028(9.32)$ & 15,781 & 5977 & 21,758 & $<0.001$ & 0.788 \\
\hline Y & 3865 (11.59) & 24,153 & 9196 & 33,349 & & \\
\hline \multicolumn{7}{|l|}{ Admission status } \\
\hline Direct & $5234(10.15)$ & 36,667 & 14,901 & 51,568 & $<0.001$ & $<0.001$ \\
\hline Transferred in & $723(16.65)$ & 3724 & 621 & 4345 & & \\
\hline \multicolumn{7}{|l|}{ APR-DRG: likelihood of dying } \\
\hline Minor & $66(0.4)$ & 6965 & 8015 & 14,980 & $<0.001$ & $<0.001$ \\
\hline Moderate & $865(4)$ & 15,769 & 5589 & 21,358 & & \\
\hline Major & $1084(10.8)$ & 8674 & 1353 & 10,027 & & \\
\hline Extreme & $3943(41.3)$ & 9004 & 544 & 9548 & & \\
\hline \multicolumn{7}{|l|}{ APR-DRG: loss of function } \\
\hline Minor† & $26(0.8)$ & 946 & 2182 & 3128 & $<0.001$ & $<0.001$ \\
\hline Moderate & $449(2)$ & 13,007 & 8750 & 21,757 & & \\
\hline Major & 2471 (11.2) & 17,983 & 4060 & 22,043 & & \\
\hline Extreme & $3012(33.5)$ & 8476 & 509 & 8985 & & \\
\hline \multicolumn{7}{|l|}{ Comorbidity index } \\
\hline Low & $4748(10.25)$ & 32,200 & 14,122 & 46,323 & $<0.001$ & $<0.001$ \\
\hline High & $1210(12.62)$ & 8211 & 1379 & 9590 & & \\
\hline \multicolumn{7}{|l|}{ Age } \\
\hline$\leq 65 \mathrm{yrs}$ & $1279(6.25)$ & 11,530 & 8945 & 20,476 & $<0.001$ & $<0.001$ \\
\hline$>65 \mathrm{yrs}$ & $4679(13.20)$ & 28,881 & 6556 & 35,437 & & \\
\hline \multicolumn{7}{|l|}{ PCS } \\
\hline $\mathrm{N}$ & $5673(10.29)$ & 39,787 & 15,333 & 55,120 & $<0.001$ & $<0.001$ \\
\hline Y & $285(35.97)$ & 625 & 168 & 793 & & \\
\hline \multicolumn{7}{|l|}{$P E^{*}$} \\
\hline $\mathrm{N}$ & $5804(10.63)$ & 39,315 & 15,293 & 54,608 & 0.172 & $<0.001$ \\
\hline Y & 154 (11.81) & 1096 & 208 & 1304 & & \\
\hline
\end{tabular}


TABLE 2. Mortality and discharge disposition: analysis of patient, hospital, and demographic factors (continued)

\begin{tabular}{|c|c|c|c|c|c|c|}
\hline \multirow[b]{2}{*}{ Factor } & \multirow{2}{*}{$\begin{array}{l}\text { Hospital Deaths, } \\
\text { n (\%) }\end{array}$} & \multirow[b]{2}{*}{ OTR DD } & \multirow[b]{2}{*}{ Routine DD } & \multirow[b]{2}{*}{ Total } & \multicolumn{2}{|c|}{$p$ Value } \\
\hline & & & & & Mortality & $\mathrm{DD}$ \\
\hline \multicolumn{7}{|l|}{ Pneumonia } \\
\hline $\mathrm{N}$ & $5534(10.30)$ & 38,366 & 15,340 & 53,707 & $<0.001$ & $<0.001$ \\
\hline $\mathrm{Y}$ & $424(19.24)$ & 2045 & 161 & 2206 & & \\
\hline \multicolumn{7}{|l|}{ Aspiration pneumonia* } \\
\hline $\mathrm{N}$ & $5101(9.69)$ & 37,264 & 15,349 & 52,613 & $<0.001$ & $<0.001$ \\
\hline $\mathrm{Y}$ & $857(25.98)$ & 3147 & 152 & 3299 & & \\
\hline \multicolumn{7}{|l|}{ DVT } \\
\hline $\mathrm{N}$ & $5784(10.65)$ & 39,175 & 15,128 & 54,303 & 0.841 & $<0.001$ \\
\hline $\mathrm{Y}$ & $174(10.80)$ & 1237 & 373 & 1610 & & \\
\hline \multicolumn{7}{|l|}{ UTI } \\
\hline $\mathrm{N}$ & $5408(10.99)$ & 34,579 & 14,639 & 49,218 & $<0.001$ & $<0.001$ \\
\hline $\mathrm{Y}$ & $550(8.21)$ & 5833 & 862 & 6695 & & \\
\hline \multicolumn{7}{|l|}{$\mathrm{SH}$} \\
\hline $\mathrm{N}$ & $4844(9.25)$ & 37,168 & 15,190 & 52,359 & $<0.001$ & $<0.001$ \\
\hline $\mathrm{Y}$ & $1114(31.36)$ & 3243 & 311 & 3554 & & \\
\hline \multicolumn{7}{|l|}{ CAD } \\
\hline $\mathrm{N}$ & 4168 (9.91) & 30,099 & 11,949 & 42,048 & $<0.001$ & $<0.001$ \\
\hline $\mathrm{Y}$ & $1790(12.91)$ & 10,312 & 3552 & 13,865 & & \\
\hline \multicolumn{7}{|l|}{ Sex } \\
\hline M & $2853(10.35)$ & 18,768 & 8787 & 27,555 & $<0.001$ & $<0.001$ \\
\hline $\mathrm{F}$ & $3105(10.95)$ & 21,644 & 6714 & 28,358 & & \\
\hline \multicolumn{7}{|l|}{ Race } \\
\hline White & $3470(9.62)$ & 25,994 & 9889 & 35,883 & $<0.001$ & $<0.001$ \\
\hline Black & $2090(13.4)$ & 11,402 & 4232 & 15,634 & & \\
\hline Hispanic & $248(8.45)$ & 2001 & 932 & 2933 & & \\
\hline Asian or Pacific Islander & $135(10.82)$ & 895 & 353 & 1248 & & \\
\hline Native American & $15(6.98)$ & 120 & 95 & 215 & & \\
\hline \multicolumn{7}{|l|}{ Primary expected payer } \\
\hline Medicare & $4258(12.49)$ & 27,606 & 6484 & 34,090 & $<0.001$ & $<0.001$ \\
\hline Medicaid & $293(8.06)$ & 2347 & 1287 & 3633 & & \\
\hline Private & $1057(7.55)$ & 8365 & 5639 & 14,004 & & \\
\hline Self & $199(7.93)$ & 1183 & 1326 & 2509 & & \\
\hline Other & $151(9)$ & 911 & 766 & 1677 & & \\
\hline
\end{tabular}

Hosp = hospital; PCS = posterior circulation stroke; PE = pulmonary embolism; $\mathrm{SH}=$ secondary hemorrhage.

* Had nonsignificant, missing values.

$\dagger$ Includes cases with no comorbidity or complications.

\section{Hospital and Demographic Factors}

Among the studied hospital factors, only hospital region (West) and location (urban) had a significant association with OTR discharge disposition $(\mathrm{p}<0.0001$ for each variable) in the direct admission and transfer cohorts (Table 2). When the same factors were studied in relation to mortality, teaching status of the hospital, bed size, ownership, and hospital region were associated with a significant $(\mathrm{p}<0.05)$ decrease in mortality during hospitalization (Table 2).

The demographic factors of sex $(\mathrm{p}<0.001)$, race $(\mathrm{p}<$ $0.001)$, and insurance $(\mathrm{p}<0.001)$ had a significant impact on discharge disposition. This significance persisted even when the cohorts were analyzed in relation to mortality during hospitalization. Blacks had the highest percentage of OTR discharge disposition (72.9\%) and mortality (13.4\%) (Table 2).

\section{Regression Analysis}

To better understand the actual impact of transfer status and posterior circulation stroke on discharge disposition, these 2 factors were tested with other demographic, patientbased, and hospital factors. Both transfer status/admission status and posterior circulation stroke were independently associated with OTR discharge disposition (Table 3). Posterior circulation stroke had an OR of 1.541 for OTR dis- 
charge disposition ( $\mathrm{p}<0.0001,95 \%$ CI 1.421-1.849) when compared with anterior circulation stroke. Patients who were transferred had an OR of 2.124 compared with direct admissions ( $\mathrm{p}<0.0001,95 \%$ CI 2.268-2.741). Aspiration pneumonia ( $\mathrm{p}<0.001$, OR 2.295, 95\% CI 1.926-2.735) and high comorbidity index ( $\mathrm{p}<0.001$, OR $1.293,95 \%$ CI 1.210-1.382) were independently significantly associated with OTR discharge disposition.

Among the demographic factors, female sex $(\mathrm{p}<0.001$, OR $1.225,95 \%$ CI $1.174-1.278)$ and black race $(\mathrm{p}=0.0008$, OR $1.749,95 \%$ CI 1.665-1.491) were independently significantly associated with OTR discharge disposition (Table
2). Hospital control (government/private ownership) did not have a significant impact on OTR discharge disposition, but large hospitals were protective against worse outcomes ( $p<0.0001$, OR 0.916, 95\% CI 0.873-0.962).

Further, our analysis showed the protective effect of insurance status, private $(\mathrm{p}<0.001$, OR $0.587,95 \%$ CI $0.521-0.661)$ and self-pay $(\mathrm{p}<0.0001$, OR $0.765,95 \%$ CI 0.670-0.873), compared with the reference "no insurance," against OTR discharge dispositions. As expected, the strongest association with OTR discharge disposition was seen in the cohort of patients with APR-DRG severity status of extreme loss of function ( $p<0.0001$, OR 20.430,

TABLE 3. Regression analysis of factors associated with discharge disposition*

\begin{tabular}{|c|c|c|c|c|}
\hline \multirow[b]{2}{*}{ Variables } & \multirow[b]{2}{*}{$p$ Value } & \multirow[b]{2}{*}{ OR } & \multicolumn{2}{|c|}{ 95\% Cl Bounds } \\
\hline & & & Lower & Upper \\
\hline DVT & 0.027 & 0.864 & 0.759 & 0.983 \\
\hline UTI & $<0.0001$ & 1.718 & 1.588 & 1.858 \\
\hline $\mathrm{SH}$ & $<0.0001$ & 1.460 & 1.287 & 1.656 \\
\hline High comorbidity index & $<0.0001$ & 1.293 & 1.210 & 1.382 \\
\hline Age $>65$ yrs & $<0.0001$ & 2.806 & 2.688 & 2.929 \\
\hline PCS & $<0.0001$ & 1.541 & 1.421 & 1.849 \\
\hline CAD & 0.01 & 1.184 & 1.129 & 1.242 \\
\hline PE & 0.111 & 0.880 & 0.752 & 1.030 \\
\hline Pneumonia & $<0.0001$ & 1.710 & 1.442 & 2.027 \\
\hline Aspiration pneumonia & $<0.0001$ & 2.295 & 1.926 & 2.735 \\
\hline Transfer-in vs direct admission & $<0.0001$ & 2.124 & 2.268 & 2.741 \\
\hline F vs M & $<0.0001$ & 1.225 & 1.174 & 1.278 \\
\hline \multicolumn{5}{|l|}{ Compared w/ white race } \\
\hline Native American & 0.847 & 0.896 & 0.845 & 1.079 \\
\hline Hispanic & 0.075 & 0.752 & 0.549 & 1.029 \\
\hline Asian or Pacific Islander & 0.079 & 0.743 & 0.533 & 1.035 \\
\hline Black & 0.008 & 1.665 & 1.491 & 1.840 \\
\hline \multicolumn{5}{|c|}{ Insurance status (compared w/ persons w/o insurance) } \\
\hline Private & $<0.0001$ & 0.587 & 0.521 & 0.661 \\
\hline Self-pay & $<0.0001$ & 0.765 & 0.670 & 0.873 \\
\hline Medicare & 0.218 & 0.871 & 0.737 & 1.464 \\
\hline Medicaid & 0.73 & 1.569 & 0.527 & 1.368 \\
\hline Hosp size (large vs small) & 0.000 & 0.916 & 0.873 & 0.962 \\
\hline \multicolumn{5}{|l|}{ Hosp control/ownership } \\
\hline Government, nonfederal & 0.372 & 0.924 & 0.851 & 1.103 \\
\hline Private, nonprofit & 0.091 & 1.105 & 0.730 & 1.342 \\
\hline Hosp location (rural vs urban) & 0.225 & 1.068 & 0.960 & 1.189 \\
\hline \multicolumn{5}{|l|}{ Hosp region w/ reference to South } \\
\hline Northeast & 0.096 & 1.003 & 0.903 & 1.142 \\
\hline Midwest & 0.355 & 0.968 & 0.903 & 1.037 \\
\hline West & 0.668 & 0.987 & 0.932 & 1.046 \\
\hline Hosp status (teaching vs nonteaching) & $<0.0001$ & 0.798 & 0.763 & 0.836 \\
\hline \multicolumn{5}{|c|}{ APR-DRG: loss of function (minor as reference) $\dagger$} \\
\hline Moderate & $<0.0001$ & 2.903 & 2.612 & 3.228 \\
\hline Major & $<0.0001$ & 6.864 & 6.152 & 7.657 \\
\hline Extreme & $<0.0001$ & 20.430 & 17.887 & 23.335 \\
\hline
\end{tabular}

* The dependent variable tested was discharge disposition (OTR vs routine).

$\dagger$ Includes cases with no comorbidity or complications. 
95\% CI 17.887-23.335) when compared with the cohort with minor loss of function (Table 3).

\section{Hospitalization Cost and Complications}

The mean cost of hospitalization including an intervention was $\$ 70,325.11$ in patients who were directly admitted and \$97,546.92 in patients who were transferred in from another facility. Box plot analysis showed outliers in each cohort; thus, a Mann-Whitney U-test was done to analyze the difference. The difference in cost was significant ( $p<0.0001$ ) (Fig. 1 left). When each intervention subset (tPA only, thrombectomy plus tPA, thrombectomy only) was analyzed, the cost was significantly higher in patients transferred in from another facility (tPA, $\$ 61,214.87$; thrombectomy plus tPA, $\$ 159,964.69$; thrombectomy only, $\$ 144,253.74$ ) versus direct admissions (tPA, \$60,366.22; thrombectomy plus tPA, $\$ 135,564.94$; thrombectomy only, $\$ 132,409.52)(\mathrm{p}<0.0001)$. However, in the tPA cohort, it was nonsignificant ( $\mathrm{p}=0.113)$.

Hospitalization cost was further analyzed by quartile analysis, and patients in whom the hospitalization cost was above the 75th percentile formed the higher cost cohort. Patient factors that can alter treatment cost during hospitalization were considered and entered in the regression analysis model. Transfer to another facility $(\mathrm{p}<0.001$, OR $2.124,95 \%$ CI 2.268-2.741) and posterior circulation stroke ( $\mathrm{p}<0.001$, OR $1.541,95 \%$ CI 1.421-1.849) were associated with higher hospitalization cost (Table 4). The strongest association with higher hospitalization cost was seen in the cohort of patients with extreme loss of function $(\mathrm{p}<0.001$, OR 9.707, 95\% CI 8.712-10.815) when compared with the cohort with minor loss of function (Table 4).

Regional analysis showed that the highest hospitalization cost was in the West $(\mathrm{p}<0.001$ compared with other regions). Mean hospitalization cost for direct admissions in the West was $\$ 99,319.21$, and $\$ 69,718.11, \$ 58,020.77$, and $\$ 62,652.54$ for the Northeast, Midwest, and South regions, respectively. Mean hospitalization cost for transferred-in cases in the West was $\$ 113,066.20$ (Northeast, $\$ 115,168.50$; Midwest, $\$ 87,059.46$; South, $\$ 75,000.50$ ).

Complications were found significantly more frequently in patients transferred in from another facility. Table 5 provides a summary of these complications.

\section{Discussion}

The cost of stroke care is increasing. Qureshi et al. ${ }^{16}$ found that hospital charges increased from $\$ 10,500$ to $\$ 16,200$ for patients with ischemic stroke from 1990-1991 to 2001-2002. In an estimate of 2005 data from the Healthcare Cost and Utilization Project (HCUP), it was revealed that the annual impact of cerebrovascular disease approximates to $\$ 8.5$ billion in hospital cost. ${ }^{18}$ According to medical expense data from the Agency for Health Research and Quality, cerebrovascular disease accounted for an expenditure of $\$ 18.84$ billion in $2008 .^{10}$ In 2010 , costs associated with cerebrovascular disease treatment rose to $\$ 20.58$ billion (Agency for Healthcare Research and Quality Household Component Summary Data Tables at http://meps. ahrq.gov/data_stats/tables_compendia_hh_interactive. jsp?File $=$ HCFY2010\&Table $=$ HCFY2010_CNDXP_C\&
TCOPT $1=\&$ TCOPT $2=\&$ ModPopCheck=Yes \&ModPop $=$ Yes $\& \_$Debug $=\&$ DDAGELOW $=\& D$ DAGEHIGH $=\& A c$ tion. $x=179 \& A c t i o n . y=19)$. These estimates included outpatient or office-based provider visits, hospital inpatient stays, emergency room visits, prescribed medicines, and home health care.

Ours is the first study (to the best of our knowledge) that has analyzed the cost involved in the treatment of acute stroke when some intervention is required as derived from the NIS database. In our study, the annual cost incurred by hospitals for "active" stroke intervention (patients who received tPA or thrombectomy or both) was $\$ 0.98$ billion in the year 2008, and it increased nearly 2 -fold in the year 2010 to $\$ 1.78$ billion. As the cost involved has become increasingly higher, it is important to analyze the expenditure and outcome of patients who were directly treated at the primary facility compared with those transferred to another facility (a possible specialty center). The question of treatment at a specialty center has become even more important in view of the recent trials that have resulted in a paradigm shift in the management of acute stroke. Some of these trials, such as the Multicenter Randomized Clinical Trial of Endovascular Treatment for Acute Ischemic Stroke in the Netherlands (MR CLEAN), included patients with NIHSS scores as low as 2 and showed significant improvement with endovascular therapy. ${ }^{4} \mathrm{~A}$ similar trial, the Endovascular Treatment for Small Core and An-

TABLE 4. Regression analysis of factors associated with hospitalization cost*

\begin{tabular}{|c|c|c|c|c|}
\hline \multirow[b]{2}{*}{ Factor } & \multirow[b]{2}{*}{$p$ Value } & \multirow[b]{2}{*}{ OR } & \multicolumn{2}{|c|}{$95 \% \mathrm{Cl}$ Bounds } \\
\hline & & & Lower & Upper \\
\hline DVT & $<0.0001$ & 1.563 & 1.390 & 1.759 \\
\hline UTI & $<0.0001$ & 1.662 & 1.563 & 1.768 \\
\hline $\mathrm{SH}$ & $<0.0001$ & 1.821 & 1.635 & 2.019 \\
\hline Comorbidity index & $<0.0001$ & 0.000 & 1.134 & 1.074 \\
\hline Age $\geq 65$ yrs & $<0.0001$ & 1.246 & 1.123 & 1.291 \\
\hline PCS & $<0.0001$ & 2.025 & 1.700 & 2.411 \\
\hline CAD & 0.086 & 0.967 & 0.801 & 1.175 \\
\hline PE & 0.576 & 0.728 & 0.801 & 1.643 \\
\hline Pneumonia & $<0.0001$ & 1.742 & 1.569 & 1.935 \\
\hline Aspiration pneumonia & $<0.0001$ & 1.421 & 1.296 & 1.559 \\
\hline Transfer-in vs direct admission & $<0.0001$ & 1.682 & 1.560 & 1.813 \\
\hline $\begin{array}{l}\text { Hosp status (teaching vs } \\
\text { nonteaching) }\end{array}$ & $<0.0001$ & 1.739 & 1.660 & 1.822 \\
\hline \multicolumn{5}{|l|}{$\begin{array}{l}\text { Hosp region w/ reference to } \\
\text { Northeast }\end{array}$} \\
\hline West & $<0.0001$ & 1.739 & 1.660 & 1.822 \\
\hline South & 0.451 & 1.234 & 0.930 & 1.127 \\
\hline Midwest & $<0.0001$ & 3.978 & 3.757 & 4.212 \\
\hline \multicolumn{5}{|l|}{$\begin{array}{l}\text { APR-DRG: loss of function } \\
\text { (minor as reference) } \dagger\end{array}$} \\
\hline Moderate & $<0.0001$ & 2.635 & 2.428 & 2.859 \\
\hline Major & $<0.0001$ & 6.487 & 5.958 & 7.064 \\
\hline Extreme & $<0.0001$ & 9.707 & 8.712 & 10.815 \\
\hline
\end{tabular}

\footnotetext{
* The dependent variable tested was hospitalization cost.
}

$\dagger$ Includes cases with no comorbidity or complications. 

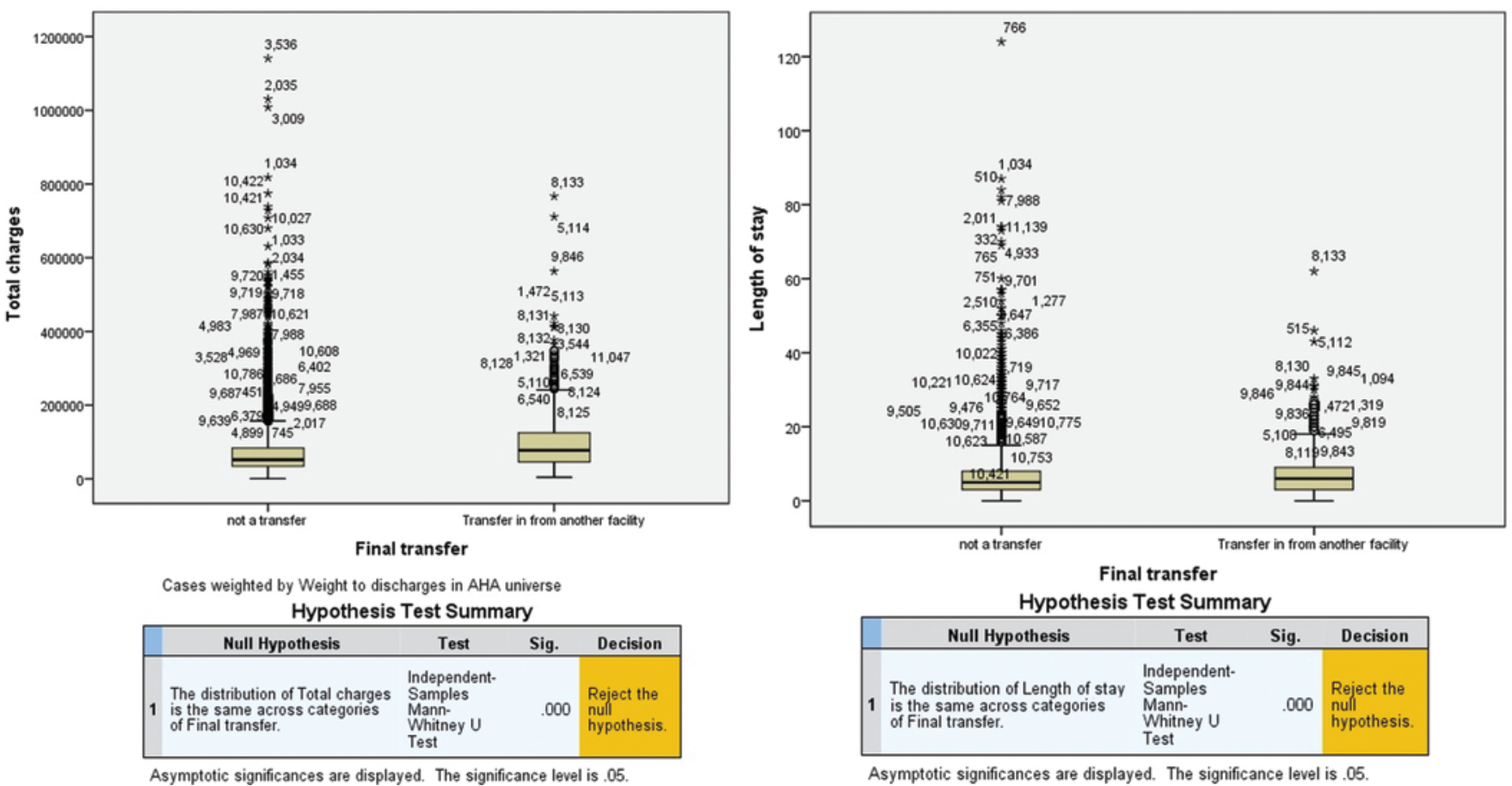

FIG. 1. Left: Box plot showing hospitalization charges (in US dollars) associated with acute stroke intervention for transferred-in versus nontransferred patients. Right: Box plot showing LOS (in days) associated with acute stroke intervention for transferredin versus nontransferred patients. The boxes indicate interquartile range, whiskers show full range, and horizontal rules indicate median values. Figure is available in color online only. $\mathrm{AHA}=$ American Hospital Association.

terior Circulation Proximal Occlusion with Emphasis on Minimizing CT to Recanalization Times (ESCAPE), also showed superiority of endovascular treatment compared with best medical therapy. ${ }^{11}$ These trials have raised the pitch for faster and better access to comprehensive stroke centers for patients with the diagnosis of acute stroke.

In our study, the mean expenditure of an active stroke intervention at the direct admission facility was $\$ 60,366.22$ with tPA alone and $\$ 135,564.94$ and $\$ 132,409.52$ for thrombectomy plus tPA and thrombectomy alone, respectively. This cost was significantly lower than the cost involved when the patient was transferred in from another facility for the same treatment $(\$ 61,214.87$ for tPA alone, $\$ 159,964.69$ for tPA and thrombectomy, and $\$ 144,253.74$ for thrombectomy alone). We found that the cost incurred was significantly higher when the patient was transferred in from another facility for intervention compared with a direct admission (Fig. 1 left). Thus, it is very important to transport the patient to the appropriate center at the outset. Further, when a patient is transferred in from another facility, the expenditure is incurred on 4 counts: for transport to the first hospital, cost incurred at the first/primary hospital, transport to the specialty center, and finally, the cost involved at the secondary facility/specialty center. Most importantly, it signifies a delay in the delivery of the definitive care, which contributes to an increase in adverse outcomes (OTR) and a dependent increase in cost of care for transferred patients.

In the present study, we included only those patients who had some form of active stroke intervention. To explain the higher hospitalization cost for the cohort trans- ferred in from another facility, we conducted further analysis that showed a significantly greater length of stay (LOS) in these patients (Fig. 1 right). Mean LOS in the direct admission cohort was 6.34 days (SD 5.86 days, range 1-124 days). Mean LOS in the transfer cohort was 7.27 days (SD 5.95 days, range 1-62 days). As the range was broad and the 2 cohorts had outliers, we carried out a box plot analysis and Mann-Whitney U-test (Fig. 1 right). We found that mean LOS was significantly greater for patients referred to another facility.

Because initial clinical condition can affect discharge disposition and hospitalization cost, we included APRDRGs. APR-DRGs are based on the clinical events that occurred during hospital stay or were present at the time of admission. APR-DRG severity cannot be used as a surrogate marker for modified Rankin Scale (mRS) score or NIHSS score at admission. However, it does provide valuable disability status data, and its inclusion in the regression analysis makes the testing of other covariates more robust.

TABLE 5. Complications and admission/transfer status

\begin{tabular}{lccc}
\hline \multicolumn{1}{c}{ Complication } & $\begin{array}{c}\text { Direct } \\
\text { Admission, } \mathrm{n}(\%)\end{array}$ & $\begin{array}{c}\text { Transferred In, } \\
\mathrm{n}(\%)\end{array}$ & $\mathrm{p}$ Value \\
\hline PE & $1175(2.28)$ & $129(2.97)$ & 0.004 \\
\hline Pneumonia & $1960(3.80)$ & $246(5.66)$ & $<0.0001$ \\
\hline Aspiration pneumonia & $2939(5.70)$ & $360(8.29)$ & $<0.0001$ \\
\hline DVT & $1370(2.66)$ & $240(5.52)$ & $<0.0001$ \\
\hline UTI & $6020(11.67)$ & $675(15.54)$ & $<0.0001$ \\
\hline SH & $3092(6.00)$ & $462(10.63)$ & $<0.0001$ \\
\hline
\end{tabular}


As expected, APR-DRG severity status of extreme loss of function had the highest odds of incurring higher hospitalization cost $(p<0.001$, OR 9.707, 95\% CI 8.712-10.815) and OTR discharge disposition ( $\mathrm{p}<0.0001$, OR 20.430, 95\% CI 17.887-23.335).

Moreover, as mentioned, patients with complications and those with more comorbidities incurred a significantly higher hospitalization cost. In the regression analysis, these factors had a significant association with higher hospitalization cost; despite these covariates, transfer status was an independent predictor for higher hospitalization cost (Table 4).

\section{Outcome}

To our knowledge, this is also the first study to document the impact of transferring a patient for active stroke intervention compared with a direct admission that included intervention. In our study, $4.5 \%$ of patients $(n=2178)$ were given tPA at the hospital to which they were transferred but not at the direct admission facility. This finding suggests the importance of raising stroke awareness at the primary hospital level. Similarly, for all patients who underwent thrombectomy alone, the majority (39.07\%) of these procedures were performed at the transferred hospital (Table 2). Tissue plasminogen activator was not given in such cases, possibly because the patient received tPA at the primary hospital or was outside the tPA window but still within the thrombectomy window when arriving at the transferred hospital. Again, these data strongly suggest that there is an incumbent delay in the delivery of definitive care by taking stroke patients to centers that are not equipped to deliver all modalities of stroke intervention. This is highly reminiscent of the state of trauma care before the development of graded trauma centers based on geographic considerations, with higher morbidity and mortality at nonspecialized units.

Transfer status/admission status became even more important when we studied its impact on discharge disposition and mortality. The percentage of routine discharge disposition fell significantly $(\mathrm{p}<0.001)$ in each treatment cohort (tPA, thrombectomy plus tPA, and thrombectomy alone) compared with the direct admission cohort (Table $3)$. When mortality analysis was performed, the difference was most significant in the tPA cohort $(\mathrm{p}<0.001)$. Several studies based on data collected from the NIS database have shown that race, insurance, sex, high comorbidities, CAD, UTI, DVT, and secondary intracranial hemorrhage can alter the discharge dispositions of ischemic stroke patients. $2,5,13,14$ To understand the impact of transferring such patients, we performed regression analysis with factors that can alter outcome as covariates. We included APRDRG severity in the regression model (Table 3) The regression model showed that despite adjusting for the above factors, transfer status/admission status was independently associated with OTR discharge disposition $(\mathrm{p}<0.0001)$. Differences in outcomes could be due to delay in the intervention owing to transport, ultimately leading to more complications.

Our study demonstrates a higher hospitalization cost at the "referred" hospital compared with the primary (direct admission) hospital, along with poorer discharge disposi- tions. Studies have shown that clinical outcomes are more favorable at high-volume centers ${ }^{6,12,15}$; a better strategy would be to transport the patient to a specialized center directly. Silbergleit et al. ${ }^{19}$ showed the cost-effectiveness of helicopter transportation of acute ischemic stroke patients. The transportation cost varied from $\$ 2214$ to $\$ 4500$. Chalela et al. ${ }^{8}$ showed the safety of air medical transport of these patients. A similar benefit was seen in acute trauma patients. ${ }^{21}$ The overall cost-effectiveness of helicopter emergency medical services in improving outcomes has been shown in other countries..$^{8,921}$ A future strategy would be to improve air transport of acute stroke patients to stroke centers. Our study has shown that hospitals spend more on patients who are referred from other centers for intervention, and the outcome of patients directly admitted is better than that of patients transferred in from another facility. The recent trend in development of comprehensive stroke centers and recognition of such categorization despite some concerns over dilution of standards to accommodate a larger number of sites is a step in the right direction. On the basis of our analysis of a large cohort of contemporary patient data derived from the NIS, we predict that development of regional algorithms to deliver the acute stroke patient rapidly to a center with all available modalities (comprehensive stroke center) is likely to significantly improve outcomes and reduce cost of care, both of which are highly desirable outcomes.

\section{Study Limitations}

This study is a retrospective analysis of the data gathered from several nationwide hospitals. This created the possibility of omissions and commissions during data entry. There also exists the possibility of coding errors or errors while extracting the data from the master database. Outcome analysis based on mRS or NIHSS scores could not be performed because this information is not available in the database. Further, it is not possible to document the mRS or NIHSS scores at the time of admission. For the reasons cited, we did not attempt to analyze the superiority of one treatment modality over other options.

\section{Conclusions}

Our study showed that the cost incurred by a hospital for acute stroke intervention is significantly higher for a transferred patient than for a direct admission. Moreover, the frequency of OTR discharge was significantly higher among transferred patients compared with direct admissions. Future strategies should focus on the means and ways of transporting the patient appropriately and directly to a comprehensive stroke center.

\section{Acknowledgments}

We thank Paul H. Dressel, BFA, for preparation of the illustrations and Debra J. Zimmer for editorial assistance.

\section{References}

1. Adamczyk P, Attenello F, Wen G, He S, Russin J, Sanossian $\mathrm{N}$, et al: Mechanical thrombectomy in acute stroke: utilization variances and impact of procedural volume on inpatient mortality. J Stroke Cerebrovasc Dis 22:1263-1269, 2013 
2. Attenello FJ, Adamczyk P, Wen G, He S, Zhang K, Russin $\mathrm{JJ}$, et al: Racial and socioeconomic disparities in access to mechanical revascularization procedures for acute ischemic stroke. J Stroke Cerebrovasc Dis 23:327-334, 2014

3. Bateman BT, Schumacher HC, Boden-Albala B, Berman MF, Mohr JP, Sacco RL, et al: Factors associated with in-hospital mortality after administration of thrombolysis in acute ischemic stroke patients: an analysis of the nationwide inpatient sample 1999 to 2002. Stroke 37:440-446, 2006

4. Berkhemer OA, Fransen PS, Beumer D, van den Berg LA, Lingsma HF, Yoo AJ, et al: A randomized trial of intraarterial treatment for acute ischemic stroke. N Engl J Med 372:11-20, 2015

5. Bhattacharya P, Mada F, Salowich-Palm L, Hinton S, Millis $\mathrm{S}$, Watson SR, et al: Are racial disparities in stroke care still prevalent in certified stroke centers? J Stroke Cerebrovasc Dis 22:383-388, 2013

6. Brinjikji W, Rabinstein AA, Kallmes DF, Cloft HJ: Patient outcomes with endovascular embolectomy therapy for acute ischemic stroke: a study of the national inpatient sample: 2006 to 2008. Stroke 42:1648-1652, 2011

7. Campbell BC, Mitchell PJ, Kleinig TJ, Dewey HM, Churilov $\mathrm{L}$, Yassi N, et al: Endovascular therapy for ischemic stroke with perfusion-imaging selection. N Engl J Med 372:1009_ 1018,2015

8. Chalela JA, Kasner SE, Jauch EC, Pancioli AM: Safety of air medical transportation after tissue plasminogen activator administration in acute ischemic stroke. Stroke 30:2366-2368, 1999

9. Choi JH, Bateman BT, Mangla S, Marshall RS, Prabhakaran $\mathrm{S}$, Chong J, et al: Endovascular recanalization therapy in acute ischemic stroke. Stroke 37:419-424, 2006

10. Go AS, Mozaffarian D, Roger VL, Benjamin EJ, Berry JD, Borden WB, et al: Heart disease and stroke statistics-2013 update: a report from the American Heart Association. Circulation 127: $6-\mathrm{e} 245,2013$

11. Goyal M, Demchuk AM, Menon BK, Eesa M, Rempel JL, Thornton J, et al: Randomized assessment of rapid endovascular treatment of ischemic stroke. N Engl J Med 372:10191030,2015

12. Gupta R, Horev A, Nguyen T, Gandhi D, Wisco D, Glenn BA, et al: Higher volume endovascular stroke centers have faster times to treatment, higher reperfusion rates and higher rates of good clinical outcomes. J Neurointerv Surg 5:294-297, 2013

13. Hoh BL, Chi YY, Waters MF, Mocco J, Barker FG II: Effect of weekend compared with weekday stroke admission on thrombolytic use, in-hospital mortality, discharge disposition, hospital charges, and length of stay in the Nationwide Inpatient Sample Database, 2002 to 2007. Stroke 41:2323-2328, 2010

14. Kimball MM, Neal D, Waters MF, Hoh BL: Race and income disparity in ischemic stroke care: nationwide inpatient sample database, 2002 to 2008. J Stroke Cerebrovasc Dis 23:17-24, 2014

15. McNeill L, English SW, Borg N, Matta BF, Menon DK: Effects of institutional caseload of subarachnoid hemorrhage on mortality: a secondary analysis of administrative data. Stroke 44:647-652, 2013

16. Qureshi AI, Suri MF, Nasar A, Kirmani JF, Ezzeddine MA, Divani AA, et al: Changes in cost and outcome among US patients with stroke hospitalized in 1990 to 1991 and those hospitalized in 2000 to 2001. Stroke 38:2180-2184, 2007

17. Roger VL, Go AS, Lloyd-Jones DM, Benjamin EJ, Berry JD, Borden WB, et al: Heart disease and stroke statistics-2012 update: a report from the American Heart Association. Circulation 125: e2-e220, 2012

18. Russo CA, Andrews RM: Statistical brief \#51: Hospital stays for stroke and other cerebrovascular diseases, 2005. Healthcare Cost and Utilization Project (HCUP) Statistical Briefs. (http://www.ncbi.nlm.nih.gov/books/NBK56044/) [Accessed August 4, 2015]

19. Silbergleit R, Scott PA, Lowell MJ, Silbergleit R: Cost-effectiveness of helicopter transport of stroke patients for thrombolysis. Acad Emerg Med 10:966-972, 2003

20. Sonig A, Khan IS, Wadhwa R, Thakur JD, Nanda A: The impact of comorbidities, regional trends, and hospital factors on discharge dispositions and hospital costs after acoustic neuroma microsurgery: a United States nationwide inpatient data sample study (2005-2009). Neurosurg Focus 33(3):E3, 2012

21. Wormer BA, Fleming GP, Christmas AB, Sing RF, Thomason MH, Huynh T: Improving overtriage of aeromedical transport in trauma: a regional process improvement initiative. J Trauma Acute Care Surg 75:92-96, 2013

\section{Disclosure}

Dr. Hopkins reports receiving non-study-related research support from Toshiba; being a consultant with Abbott, Boston Scientific, Cordis, Micrus, and Silk Road; having financial interest in AccessClosure, Augmenix, Boston Scientific, Claret Medical, Endomation, Micrus, and Valor Medical; being on the board, a trustee, or holding an officer position with AccessClosure and Claret Medical; being on the speakers' bureau at Abbott Vascular; and receiving honoraria from Bard, Boston Scientific, and Cordis. Dr. Levy reports being a shareholder or having ownership interests in Intratech Medical Ltd., Medina Medical, and Blockade Medical LLC; being a principal investigator for Covidien US SWIFT PRIME Trials; and receiving compensation from Abbott for physician training. Dr. Mokin reports receiving a grant from Toshiba. Dr. Siddiqui reports having financial interest in Hotspur, Intratech Medical Ltd., StimSox, Valor Medical, Blockade Medical, and Lazarus Effect; being a consultant with Codman \& Shurtleff, Inc., Concentric Medical, ev3/Covidien Vascular Therapies, GuidePoint Global Consulting, Penumbra, Stryker Pulsar Vascular, MicroVention, Lazarus Effect, and Blockade Medical; being on the speakers' bureau at Codman \& Shurtleff, Inc., and a national steering committee member for the Penumbra, Inc., 3D Separator Trial, Covidien US SWIFT PRIME Trials, and MicroVention FRED Trial; being on the advisory boards for Codman \& Shurtleff and Covidien Neurovascular; and receiving honoraria from Abbott Vascular, Codman \& Shurtleff, and Penumbra, Inc. Dr. Snyder reports receiving non-study-related support from Toshiba, Covidien, and The Stroke Group; being a consultant for Toshiba; and receiving honoraria and being on the speakers' bureau for Toshiba, Covidien, and The Stroke Group.

\section{Author Contributions}

Conception and design: Sonig. Acquisition of data: Sonig. Analysis and interpretation of data: all authors. Drafting the article: Sonig. Critically revising the article: all authors. Reviewed submitted version of manuscript: all authors. Statistical analysis: Sonig, Lin.

\section{Correspondence}

Adnan H. Siddiqui, University at Buffalo Neurosurgery, 100 High St., Ste. B4, Buffalo, NY 14203. email: asiddiqui@ubns. com. 